\title{
Evaluation of the Thermal Comfort in the Design of the Museum Routes: The Thermal Topology
}

\section{* Ph.D. Candidate SELMA SARAOUI ${ }^{1}$, Dr. AZEDDINE BELAKEHAL ${ }^{2}$, Dr. ABDELGHANI ATTAR ${ }^{3}$ Dr. AMAR BENNADJI 4}

' Department of Architecture, University of Bejaia, Algeria.

${ }^{2}$ Laboratoire de Conception et de Modélisation des Formes et des Ambiances (LACOMOFA), Department of Architecture, University of Biskra, Algeria.

${ }^{3} \mathrm{MCB}$ at the Department of Architecture, University of Bejaia, Algeria.

${ }^{4}$ The Scott Sutherland School of Architecture and Built Environment, the Robert Gordon University, UK

E mail: saraoui.selma@gmail.com ,E mail: belakehal@gmail.com , E mail: attar.a.ghani@gmail.com , E mail: $\underline{\text { a.bennadji@rgu.ac.uk }}$

\section{ARTICLE INFO:}

Article history:

Received 15 July 2018

Accepted 23 September 2018

Available online 13 October

2018

\section{Keywords:}

Segments;

Route;

Thermal comfort;

Design;

Topology.

This work is licensed under a Creative Commons Attribution - NonCommercial - NoDerivs 4.0. "CC-BY-NC-ND"

\begin{abstract}
A B S T R A C T
Museums are nowadays among the most popular projects for the public, the concept of thermal comfort in museums is often treated after the realization. Even if in the design, the architect shows a particular intention to work with daylight which is considered for these projects as main, the architect often considers certain elements that have an influence on the energy balance of these projects such as: orientation, building materials. The museum route is the key to the success of any museum project, it is the space of the visitor, the space in which he is invaded by sensations. In this study, we will first evaluate the thermal comfort in the museum as a whole (building) and then through its route. The objective is to guide reflection in the design of the museum towards the route in order to reduce energy consumption. In order to carry out our study, some European museums were analysed by means of simulation, according to the thermal comfort of their designs for the most unfavourable conditions, then by a thermal analysis of the museum route according to the segmentation principle using the average radiant temperature. This method allowed us to bring out correspondences between the architectural form and the route. Finally, the segmentation method constitutes the basis of a new methodological approach called "thermal topology" based on the discontinuities of the temperatures in the route.
\end{abstract}

JOURNAL OF CONTEMPORARY URBAN AFFAIRS (2018), 2(3), 122-136.

https://doi.org/10.25034/ijcua.2018.4727

www.ijcua.com

Copyright $@ 2018$ Journal Of Contemporary Urban Affairs. All rights reserved.

\section{Introduction}

The birth of architecture had always been linked to the human being and his needs. Theories on the architectural space have
*Corresponding Author:

Department of Architecture, University of Bejaia, Algeria.

E-mail address: saraoui.selma@gmail.com 
passed from the metric dimensional character to the ambient psychological character. Reflections on the human body have shown that the body does not stop at the surface of the skin, it has an immaterial boundary called bubble that is located in close proximity to his body. (J.Cousin, 1980)

Thus, it will be necessary to imagine that the body is included in a bubble which is also composed of several layers taking the form of a protective eclamptic sphere. Man is thus surrounded by several spheres of variable dimensions; these variations are due to his way of moving in space and the route between several spaces. These variations affect human man's behavior and his ways of appropriating space. The requirements of the human being as to his space are multiple, it can be noticed that from our reading, there are three ways of appropriating the space, a very personal way making it private, a way slightly personal making it semi-public, and a not personal way making it public.

The house is currently considered as the private space of the human being, many are the research works that deal with its aspects, however there are also projects that are considered by the human being as private with varying degrees of change such as offices, or work offices or even schools, hospitals ... in our era there are also many project intended for the general public, we find shopping centers, theaters, museums...

The museum has a public character because it is designed and intended since the beginning of its appearance to the public, however it also has its private property and many characteristics in relation to its user who is its visitor. Visitors must be transported by their emotions and live a very personal adventure in a space intended for the public

\section{Literature Review}

\subsection{The museums a "place" for the public:}

Previously, the architecture of the museum, directly inherited from the great princely residences, had been adapted to become at the same time the setting, the decoration of a private collection; then a public, and place of its ideal contemplation. The laws derived from the theories of "Gestalt" have developed the design of these spaces. They are not the only ones, there are also the various studies carried out in the company of visually impaired people, which made it possible to establish some rules in the perception of space. Certain principles of the psychology of perception can also find an application in architecture and especially in museum architecture.

For a person who has all his senses, the experience of architecture is primarily visual (sense of movement). The movement of the body, even if it is not one of our five senses, offers us the measure of things and space. The route, the visit, allow the appreciation of the grandeur. We note that the exploration of a space is carried out by simple gestures such as approaching, moving away, going around, going up, going down, penetrating, etc. These actions invite us to control what we want to see, hear, smell, taste, touch in a given environment.

During an exhibition, the visitor perceives and appropriates an ambience, and at the same time, "dialogue" with what he sees, hears, or touches, etc. It is no longer in a "space" (quantifiable volume, whose physical dimensions and surface can be determined), it is located in a "place" that has a history and that we will discover. The "place" is the result of a state of mind, a feeling of well-being or malaise, a feeling.

\subsection{The design of contemporary museums:}

In this paper we will focus on contemporary museums, with an overview of the steps that the museum has taken to reach its present complete form, and finally, the relationship between its external and internal aspect thanks to the notion of the route.

\subsubsection{An overview of the evolution of the design:}

The appearance of the museum design had evolved, according to I. Bayón Juan (2013) in the city of the 19th century, the museum was consolidated as an important building in the urban context with a social function, the consolidation of several elaborate and defined models generated new typological qualifiers i) the Museum-temple, ii) the Museum-palace, ii) the Composite Museum.

The great social and cultural transformations of the 20th century changed the concept of the museum, its social function and the way it was exhibited. The museum will no longer be a national sanctuary of art or science, but a tool for the conservation and transmission of knowledge. (I. B. Juan, 2013)

In the post-war period, a new type of museum appeared, the museum as a "white cube" of modernity, linked to the universal space of Mies van der Rohe. The first reactions against the white cube and the museum's association with the mausoleum began to appear in the 1970s. 
Van der Rohe's ideas for spaces have been taken up by a new generation. The museum had ceased to be a temple or a treasure house, the best example of these new ideas was the Centre Pompidou opened in 1977.

In the $21^{\text {st }}$ century the museum surpasses all others in its symbolic character. For this, the architecture of the museum has become a gigantic sculpture on a tray or a recognizable silhovette tower. The most representative museum of this new image of monumentality and the media is the Guggenheim in Bilbao. (I. B. Juan, 2013)

The design of the museum went through four main stages: i) The collection of objects as a sacred act: one rarely exposed to the public that during the festivals according to the period and the dominant religious belief of the time, it was practiced at temples, churches, While the collections were in the hands of the church, exposed in temples and cloisters, there was no need to create special spaces for them, ii) Presentation to the public: Everything changed when collectivism became secular and began to be exercised by princes and nobles. This is how the need to develop new types of spaces to preserve and exhibit is born. this period of visual design appears according to the historical chronology: the studios of the Renaissance princes, the palaces of Belvedere, the galleries, The creation of object cabinets, iii) as varied function: Baroque art brought a flourishing of the art by encouraging the spaces of exhibition for a better valorization of the collections, it is at this time that one conceived the first architecture for the conservation and the exhibition of the collections, The museum opened in 1683, and had to wait until the 19th century so that the operation of removal of the collections can be carried outiv) varied design: according to the content, the architectural form and the current of the architect; according to the routes,... (I. B. Juan, 2013)

In the contemporary museum the concept of the route is the key element of the design of the museum since its appearance, we will now see how it is treated in the museum.

\subsubsection{An interior design and the notion of the route:}

Le Corbusier (1977) had highlighted the fact that architecture is a journey, with its concept of "architectural walk". If villas, religious buildings, etc., offer architectural walks, it is obviously the museums that are the clearest examples. Jean-Raphaël Pigeon (2013) notes that it is only possible for man to visualize himself in his route if he becomes aware of his environment through his body, this awareness allows a better understanding of architectural space. The first relationships between man and the route refer to visual abilities, man tends to understand the environment in which he finds himself and appropriate it through decoding information that space sends him.

J-R-Pigeon (2013) evokes the works of J Cousin, the use of the bubble by the latter can better define the relations between man and his space and beyond the route, the bubble is much more than a series of layers extending on the periphery of the human body. It does not have fixed dimensions or a particular shape, but changes in the spatial route according to the movements of the body, it marries the body at a certain distance, but can expand, widen, or also compress itself according to the context. The location of the components of the architectural route (such as transition and intermediate spaces) have a particular importance and influence on the users of the route. However, the direction taken in the user's route, through the spaces, influences the perception of the latter.

The concept of route is not easy to define, because of its polysemy. We can adopt, for example, the definition of LAROUSSE (2009, p. 356): "it is the route or route followed to go from one point to another". Common sense gives various meanings. Showing the complexity of this term: (path, circuit, route, triathlon, course, crossing, stage, etc.). For some researchers, the route represents the movement of the body in space. For others, it is described as a designvisit interaction, the route being taken into account according to the context. With the route, the simple act of moving begins to make sense.

Many solutions to traffic principles have been developed; they fall into three categories according to their form (Mariani. R, 2000). (i) The "linear" route: an obligatory scheme, (ii) The "labyrinth" route: no traffic constraints, (iii) The "centered" route: The public is free to choose the route of its visit.

This typology proposed by Mariani. R (2000), is very complete if we associate it with the one proposed by Jean Davallon linked to the three levels of exhibition: i) the conception (thought route), ii) the setting in exhibition (proposed route), iii) and the visit (lived route).

However, this typology proves insufficient if we compare it to the work carried out by A. Borie and al (1985) and P. Panerai and al (1983), we have noticed for the same typology several other sub-typologies are associated, and after a reading of the two proposed typologies we 
summarized them as follows (Table 1):

Table 1. Different route configurations.

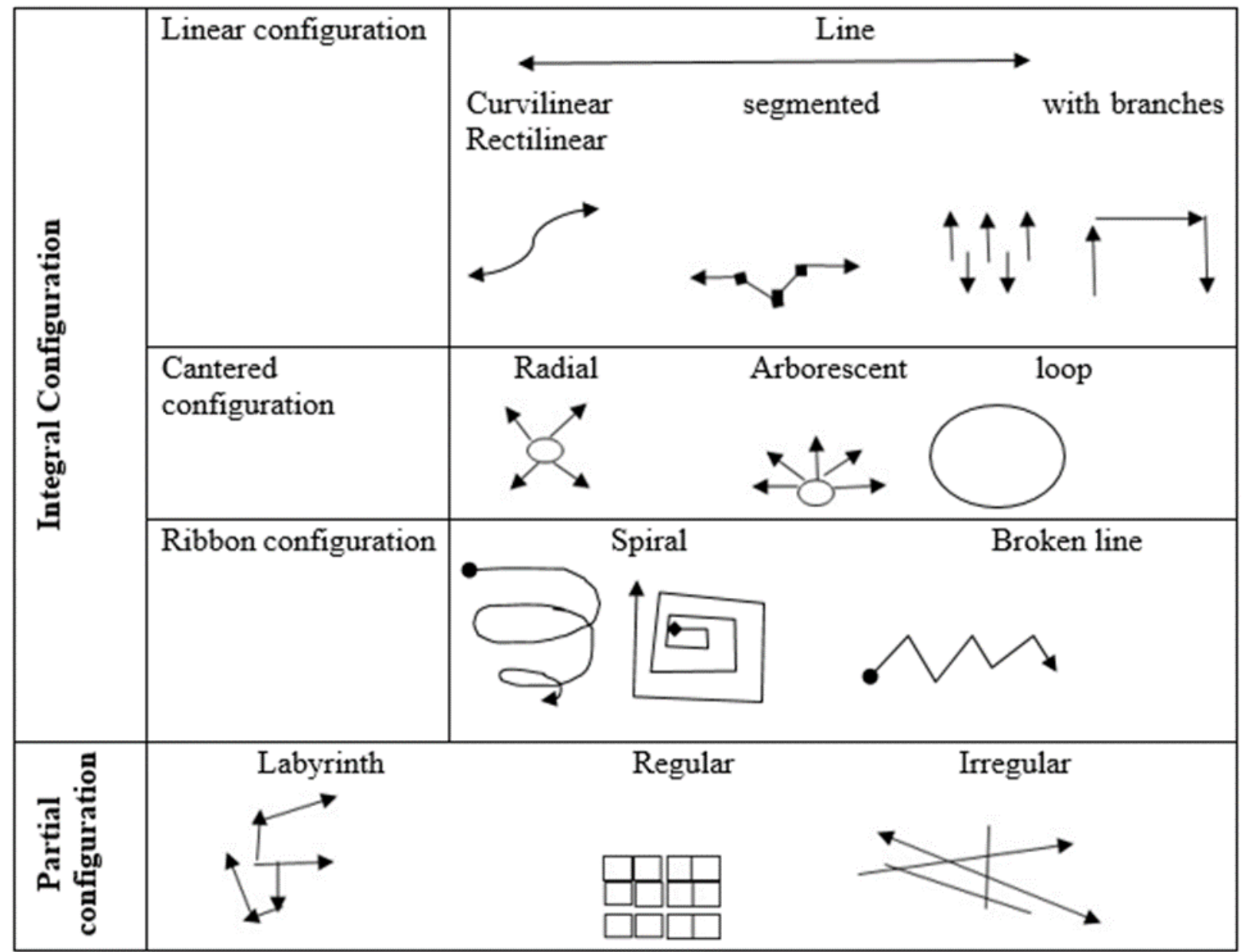

\subsection{The notion of comfort in the museum and thermal comfort:}

If we take the research carried out on museums from the angle of comfort, we will realize that the first aspect of comfort that researchers deal with is visual comfort, this is due to the initial function of the museum, which is the exhibition of works of art, if the visitor is there it is to visually appreciate the exhibition. The element of ambience linked to the visual comfort that is often treated in museums is the light, it is studied not for the comfort of the user and the success of the exhibition but also its influence on the works of art (deterioration).

However, despite the importance of light and visual comfort, there is also another type of comfort that can influence the success of the exposure is thermal comfort. This comfort is linked to the thermal environment often very much influenced by the architect's choices during the design with regard to the choice of materials... it is mainly linked to the conditions of temperature, humidity and wind as the users are exposed, but it also concerns the works of art and their lives, since in the museum it will be necessary to maintain a precise temperature and relative humidity for the maintenance of the works. It is very important to specify that the thermal performance will say as much about the energy performance, generally expressed in kilowatt-hours of primary energy consumed for $1 \mathrm{~m}^{2}$ and over a year (KWh-ep/ $\mathrm{m}^{2}$.an), the energy performance of a building designates its ability to limit energy consumption within a project, taking into account the quality of its heating equipment, but perhaps above all, its thermal behavior. The latter refers to the evolution of temperatures inside the building. (H.T Minassian, 2014)

Returning to thermal comfort, and starting with the users, the first essential condition to provide thermal comfort to a person is to balance his energy balance. The calorific power produced by the metabolism must be equal to the power dissipated in the environment by the five exchange means. (M. Le Guay, 2009) Thermal comfort is linked to energy performance, we are now seeking to make energy performance 
optimal, and it is by improving thermal comfort that this will be done.

Research in the thermal field concerning the museum without very rare and since we are interested in contemporary space we quote the work of Philippe Rahm (2005) in which he speaks of the birth of a new thermal approach with the free plane of Le Corbusier, he begins from the observation that the way of heating a space passes by heating each sub-space separately, and therefore he proposes with the same principle of the free plan or everything communicates to try to think of the whole house as a global atmosphere, this led to the birth of a new concept which is the thermal landscape.

Philippe Rahm had first of all tried to found a new architectural language linked to the thermal aspects and inspired by the values of the invisible. He then adopted the concept of the Gulf stream which is based on: i) the creation of an invisible, complex and rich thermal landscape, defined according to multiple zones of different temperatures as many climates, sensitivities, territories, ii) In this architectural design process, an atmosphere is created first, before the program, before the spatial forms, iii) It is then that the program is placed in space, looking for sensual thermal conveniences that cross localized ambient temperature criteria, clothing, physical activity. (P. Rahm, 2014)

In the case of museums, we can mention his work on the THERMAL DISTORSION for the Contemporary Art Gallery in Grand Palais (Paris, 2009), which first takes place through the zoning of activities, defining space by nuance of heat that generates different zones and functions (Working seated: $21^{\circ} \mathrm{C}$, visiting walking: $16^{\circ} \mathrm{C}$, Storing: $12^{\circ} \mathrm{C}$ ). He therefore established from these needs a design according to the temperatures of the space to be designed.

Rahm's work is more than interesting insofar as he begins to analyze before designing and according to that he designs. The observation made on the case of European museums is that the thermal comfort component is often linked to the construction phase, the architect chooses the materials, proposes a particular orientation of the projects and the interior spaces, sometimes use software for the calculation and estimation of the energy balances related to the heat of his building, except that the real heating and airconditioning powers to install his estimate once the project is completed.
In the case of museum projects realized with a particular architectural form, is there a relationship between the chosen form and thermal comfort for the most unfavorable conditions (daily and seasonal? and how does the choice of the course participate to make the thermal comfort during the visit better? Can better thermal comfort conditions be expected from the project design phase?

\section{Methodology and case study \\ 3.1. Methodology}

The element that we will use to evaluate the thermal comfort in this paper is the mean radiant temperature (MRT). This last represents from a theoretical point of view one of the elements with major influence on the comfort, it is the average of the surface temperatures of the walls which surround the person, it allows to give an idea on the resulting temperature of the comfort which is calculated by the relation: Resulting temperature $\approx$ (Ambient + mean radiant temperature) / 2

\subsubsection{Evaluation of the comfort of the building:}

We first calculate the different coefficients of form, of compactness and the ratio surface loss / living area in order to obtain information on the thermal capacities of each architectural volume.

We modelled after reduced models of our case studies with their real dimensions, their climatic files and all the characteristics of the construction materials and the context. We then simulated the thermal comfort as a function of the mean radiant temperature using the Ecotect 05 software, the simulation was carried out in several stages as follows:

- The plan views of the analysis grids for the critical hours of the most unfavorable day according to the season, we obtained 6 representative results by plan views. In this regard, we cite the case of the first floor of the Acropolis Museum in Athens (Table 2). 
Table 2. Variation of the mean radiant temperature in the Museum of the Acropolis of Athens

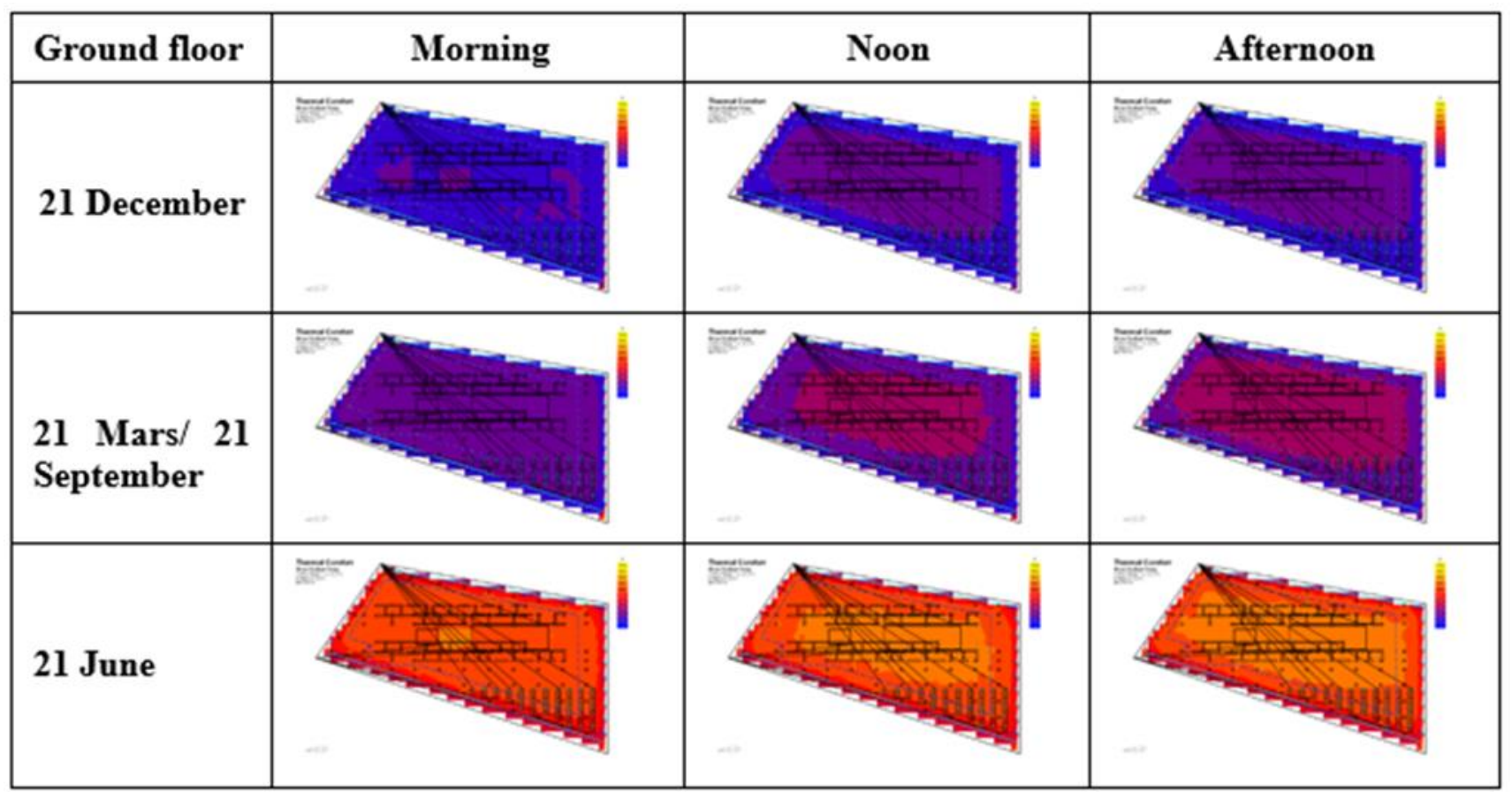

- We determined the recommended radiant temperature and compared it with the simulation results to obtain the percentages of the temperatures in the interior building spaces that respect this temperature.

The correspondence between the different case studies allowed us to make a first reading.

\subsubsection{Assessment of thermal comfort in the} museum route:

We then took the schematic results of the resulting mean radiant temperatures and on these we drawn the route, considering each colored part of the plan with a temperature as

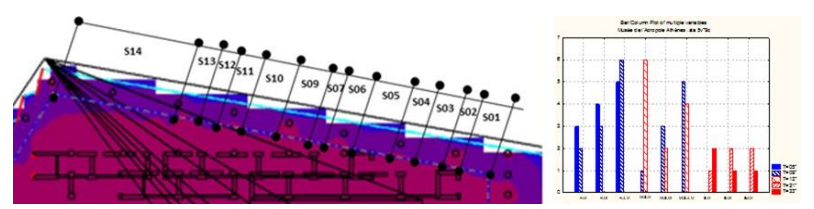

segments a part, we calculated the number of segments for each temperature and from this calculation we determined the temperature

Figure 1: Schematic segmentation, and graph of number of segments by temperature (source: author, 2018)

\subsubsection{The correspondence between the two} methods of analysis:

It is by means of the Statistical 07 software that we will proceed to carry out correspondences between the various parameters analyzed by means of a multivariate analysis. All methodology had been explained in Figure 02. 


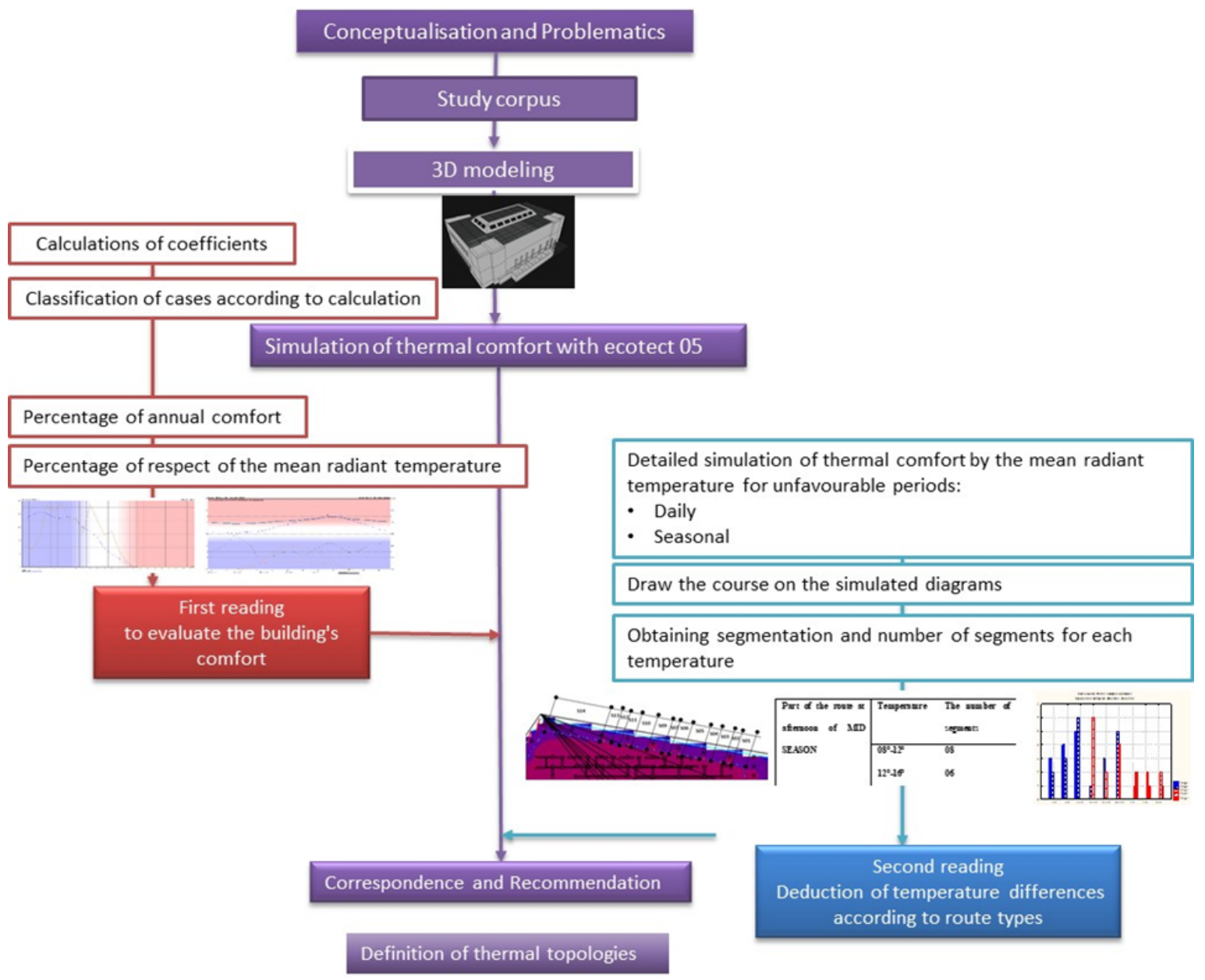

Figure 2: Methodological principle (source: author, 2018)

\subsection{Case studies:}

We have chosen our case studies according to a selection criteria grid, and we quote to this effect.

\subsubsection{Architecture and architectural form: It} should be noted that the selected museums all belong to the same historical period (19802008), museums where the architect had tried to display a particular intention to work with the daylight given the function of exposure (orientation, materials, daylight,) which will have a particular influence on thermal comfort. For the plan shape based on the optimum which varies according to the latitude of place. Our museums are all located on latitudes between $\left(37^{\circ} \mathrm{N} \_59^{\circ} \mathrm{N}\right)$ and altitudes which vary between 0 and $300 \mathrm{~m}$.

\subsubsection{Geometry, shape and compactness} coefficients: The size and geometry of the building partly determine the heating and cooling requirements. We have therefore classified our selected cases according to their shape coefficient, representing the ratio between the surface of the envelope and the habitable volume $\left(\mathrm{m}^{2} / \mathrm{m} 3\right)$, it indicates the degree of exposure of the building to climatic factors, it is a very important criterion in the thermal evaluation of the building but delicate to apply because it depends on several factors, such as the geometric shape, the size and the mode of contact of the buildings. (Roger Camous et al, 1979).

3.2.3. The orientation: The southern exposure is interesting because the sun is high and it is easy to protect oneself. It is the most favorable exposure in summer after full north, while being the best in winter. For that we chose museums oriented South or South-East or South-West.

So, we have proposed, according to the architectural form and in relation to thermal comfort, 09 museums presented in the table 3: 
Table 3. Summary of case studies and coefficients.

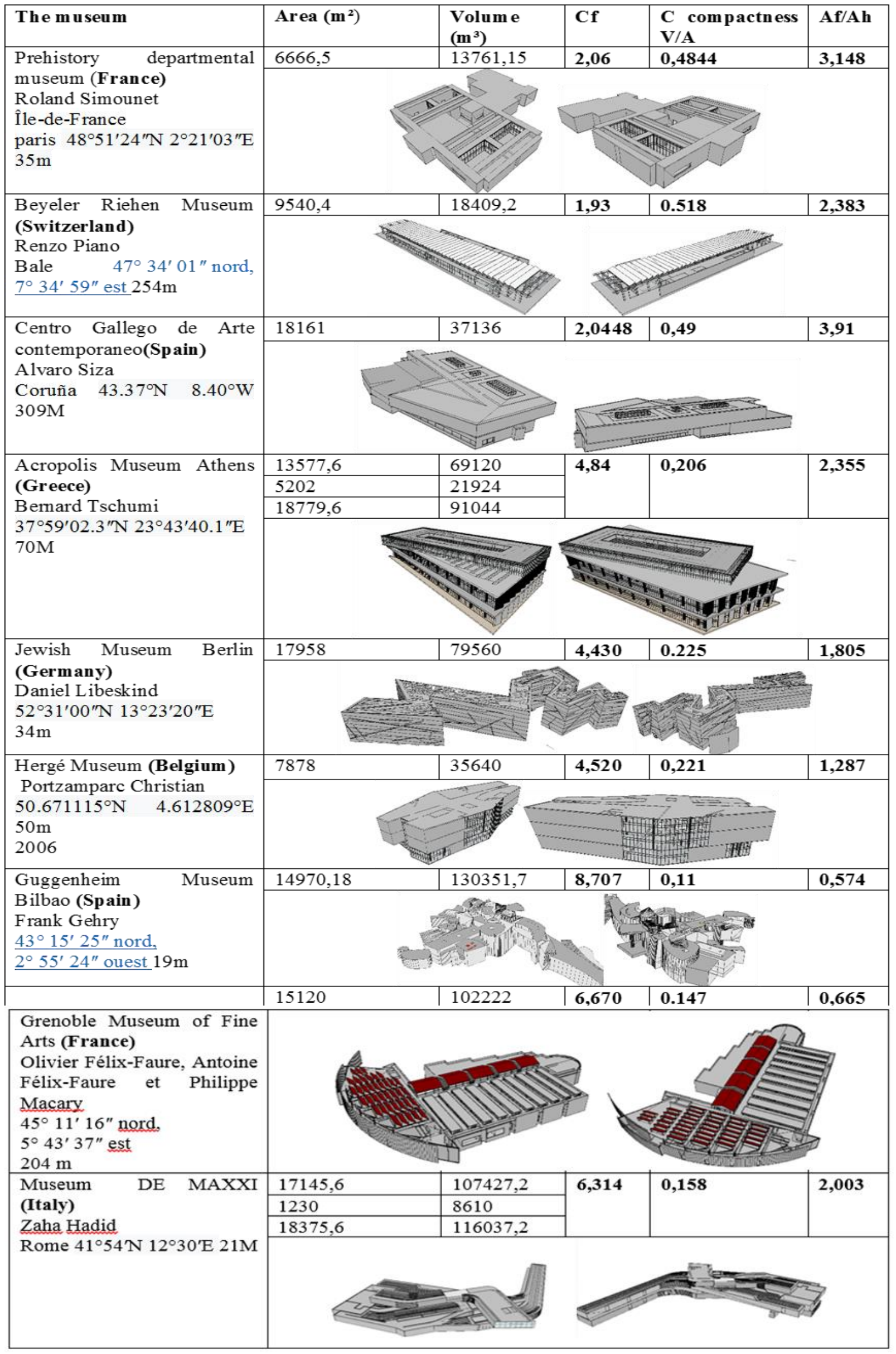




\section{Results and discussion:}

4.1. Evaluation of the comfort of the building: In relation to the coefficients

For the coefficient of compactness, we found very varied results, the Bilbao Museum presents the lowest coefficients $(0,11)$ compared to the proposed museum, however the Jewish Museum of Berlin and the Hergé Museum and the Maxxi and the Acropolis Museum Athens have a coefficient in the same interval $(0,15$ and 0.25). The prehistoric departmental museums, the Beyeler Riehen and centro Gallego de Arte contemporary have practically the same coefficients $(0,5)$.

In the case of the ratio of loss area to living area, we did not find any relationship between the results obtained for the different case studies. We go from 0,5 for the case of Bilbao to 1,2 for the Museum of Hergé, 1,8 for the Jewish Museum, the Museum of the Acropolis Athens, the Beyeler Riehen between 2 and 2,3 and finally the great values for the Prehistoric Departmental Museum and centro Gallego de Arte contemporary $\leq 3$.

These coefficients do not give us a plausible reading of the thermal quality of buildings, the most interesting from a scientific point of view is the ratio surface loss / living area, but for our study cases there is a variation between the floor area and the footprint which makes the relationship between the results very subjective. However by the coefficients of form we can already classify our museums into three formal categories: i) museum of simple form $(\mathrm{C} f \approx 2)$ : Prehistoric departmental museum, the Centro Gallego de Rate contemporaneo and the Beyeler Riehen, ii) Museums of simple form modified to $50 \%$ (see $\approx 4$ to 5): the Jewish Museum of Berlin, the Hergé Museum and the Museum of the Acropolis Athens. And finally, the museum with complex form (Cf: 6,3): the museums Guggenheim Museum Bilbao, DE MAXXI and Grenoble Museum of Fine Arts.

\subsubsection{The percentage of annual thermal comfort and the respect of the MTR:}

After the simulation we obtained the percentage of the overall comfort (Table 4) of the building and we can say that for all museums there is no particular relationship being the results all museums achieve almost $50 \%$ percentage of comfort. 


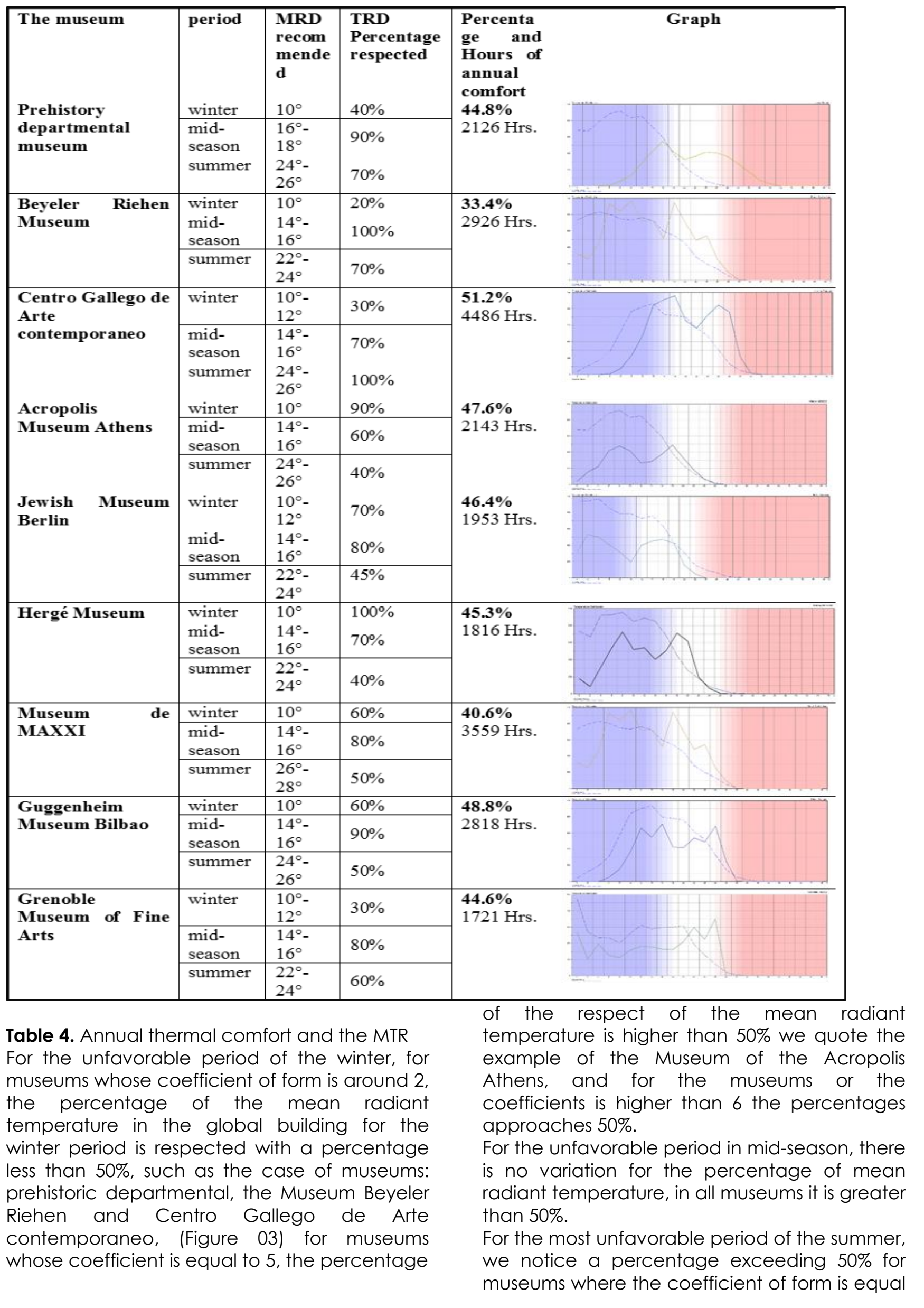


to 2 such as the case of the Centro Gallego de Arte contemporaneo, for the rest of the cases it is considered as average approaching $50 \%$.

This reading does not offer any particular information with regard to the notion of comfort from conception, and despite the disparities that may exist, it does not present any particularity of thermal point specific to the museums in the corpus of study.

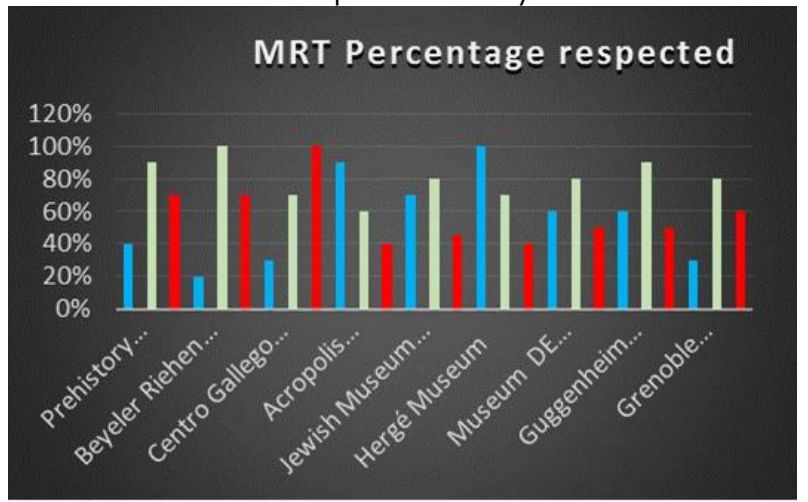

$\square \quad$ Temperature difference for winter Temperature difference for summer Temperature difference for middle season

F

igure 3: Diagram of the percentages of the MRT in the study cases

\subsection{Assessment of thermal comfort in the museum route:}

\subsubsection{Differences in mean radiant temperature} in winter:

The differences of mean radiant temperature are present within the route of two museums of case studies which are: Museum of the Acropolis Athens, and the Prehistoric Departmental Museum. (Figure 04) These differences characterize the three periods of the day when we passed for example in the case of the Acropolis Museum from 03 segments of $05^{\circ}$ and 02 segments of $09^{\circ}$ in the morning of the coldest day to 04 segments of $05^{\circ}$ and 03 segments of $09^{\circ}$ at noon, and 05 segments of $05^{\circ}$ and 06 segments of $09^{\circ}$. The correspondence also shows the total absence in these cases of a study of radiant mean temperature differences for the summer period.

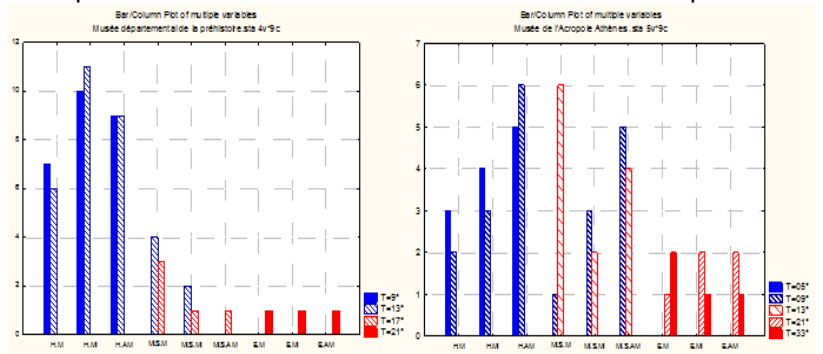

Figure 4: Diagram of variation in number of temperature segments, daily and seasonal variations
If we return to the initial segmentation of the route according to temperatures, we will notice that for these two cases (Figure 05) the visit begins from the same point and also ends in the same point, the route is considered linear for the visit but from a conceptual point of view it is rectilinear centered.

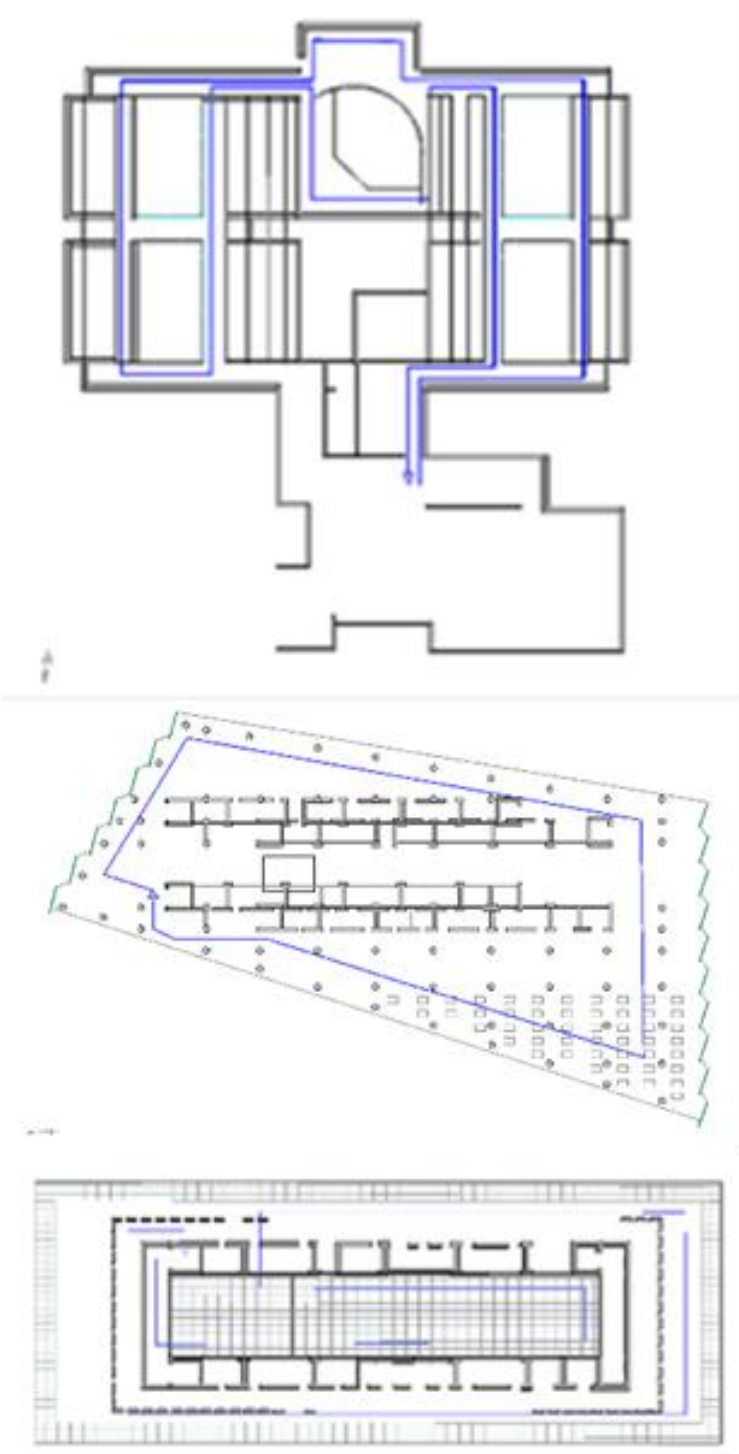

Figure 5: the route plan for the case of Prehistoric Departmental Museum and Museum of the Acropolis

\subsubsection{Differences mean radiant temperature in summer:}

These types of Differences characterize three museums of our case studies which are the Beyeler Riehen Museum, The Centro Gallego de Arte contemporaneo and the Hergé Museum, with a total absence of temperature differences during the winter period (Figure 06). We cite the case of the Beyeler Riehen museum, where we notice according to the graph that for the morning of the hottest day the route consists of 03 segments, a first one with a mean radiant temperature of $18^{\circ}$, and 
02 segments where the temperature is $22^{\circ}$, at noon for the same day the route will have 03 temperatures, $18^{\circ}$ on a segment, $22^{\circ}$ on 10 segments, and finally $30^{\circ}$ on 07 segments. For the afternoon of the hottest period we will have 02 segments of $18^{\circ}$, and one at $22^{\circ}$.

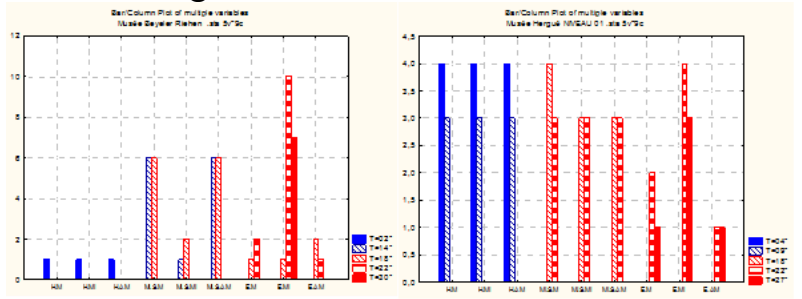

Figure 06: Diagram of variation in number of temperature segments, daily and seasonal variations

The route for these three case studies is of the same nature as it appears in the Figure 07, it is considered linear for the visitor, from the conceptual point of view, the linearity of this route can be in the case of the Museum Beyeler Riehen segmented, the Centro Gallego de Arte contemporary adopt the form of a zigzag and finally the Museum Hergé be labyrinthine in nature.
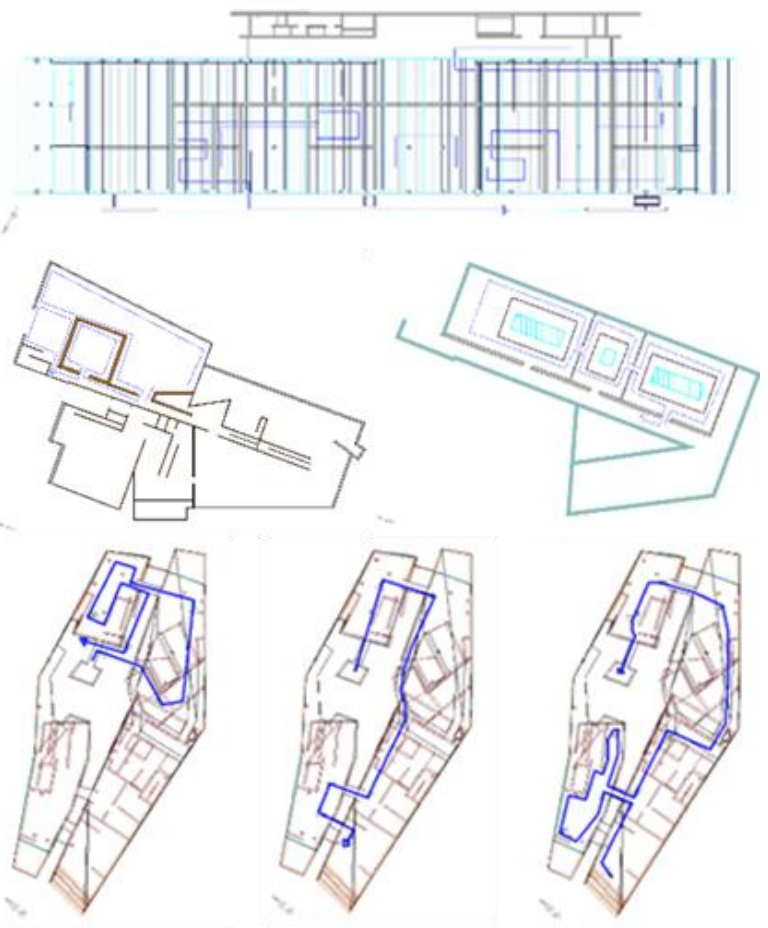

Figure 07: the route plan

\subsubsection{Differences in the mean radiant temperature in mid-season:}

These differences are the most important for our study cases, given the fact that they can extend over a long period of the year that is 06 months, there are two groups of this type of difference completely opposite, the first is the one where the differences of the mean radiant temperature are present, it includes the Jewish
Museum in Berlin and the MAXXI Museum in Rome (Figure 08).

For this purpose we mention the case of the Jewish Museum of Berlin or for the two periods of the mid-season, for the morning $02^{\circ}$ and $08^{\circ}$, at midday the distribution will remain with equality but we will have 04 segments of each temperature $02^{\circ}$ and $08^{\circ}$, the route will be composed of 04 segments, divided equally on two temperatures, for the afternoon we will have three temperatures, 02 segments of $02^{\circ}$, 07 segments of $08^{\circ}$ and 06 segments of $12^{\circ}$.

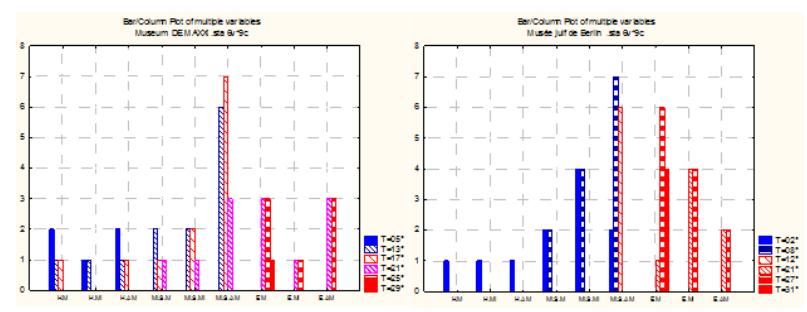

Figure 08: Diagram of variation in number of temperature segments, daily and seasonal variations

The second group is the one where these Differences are absent and we find two types of museums in this category, the Museum of Modern Art and Architecture in Stockholm and the Guggenheim Museum in Bilbao.

In the case of the Guggenheim Museum in Bilbao, the route consists of a single segment with a mean radiant temperature of $09^{\circ}$ and those for the three periods of the day. In the case of the Museum of Modern Art and Architecture in Stockholm the route consists of 05 segments spread out at 03 over a temperature of $05^{\circ}$ and 02 segment for a temperature of $09^{\circ}$.

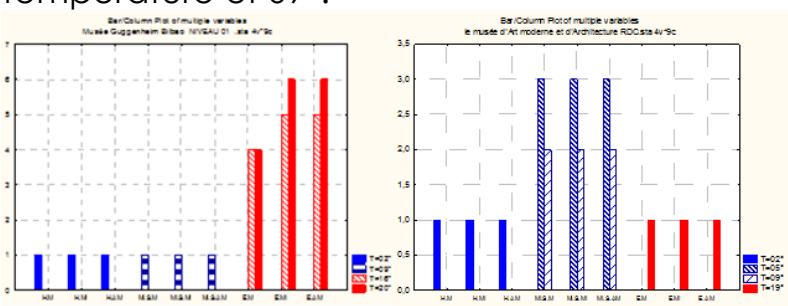

Figure 09: the route plan

For these four types of museum buildings in Figure 10, the route is labyrinth type, however for the Maxxi and the Jewish Museum this labyrinth has a conceptual character of linearity, and for the Museum of Modern Art and Architecture in Stockholm and the Guggenheim Museum in Bilbao, a perfect labyrinth. 


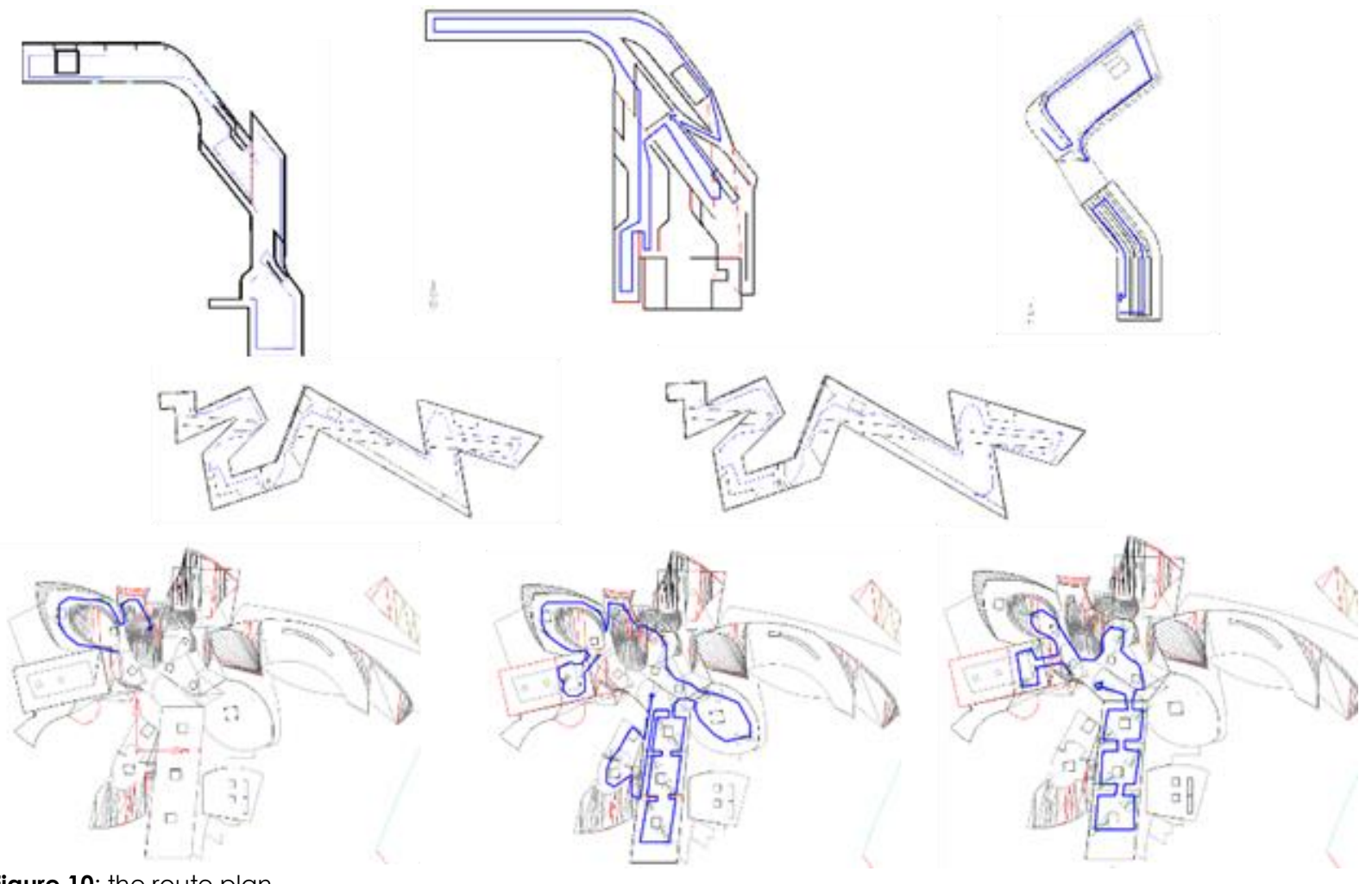

Figure 10: the route plan

\subsection{Correspondence and Recommendation:}

First, we studied the correspondence between the comfort of the building and that of the route with the software statestica 07 . This recommendation concerns directly the museums of our case studies and those of the same formal configuration, the recommendation will take effect if we respect from the design: Optimal shape / appropriate route / optimal mean radiant temperature:

- The optimal architectural form is the simple form (primary), simple forms are characterized by the existence of temperature differences that will last no more than 03 months (the time of a season). For the type of route, we recommend a route with Full Configuration, all varieties are required (simple, centered, or zigzag).

- The mid-season differences which can affect the museum route over a period of 06 months, very often characterize the architectural forms having kept $50 \%$ of their simple primary form, it will be necessary to propose the most compact architectural forms possible and without disengagement, as far as the route is concerned, we propose the routes with Integral Configuration.

- The mid-season differences are also absent in the case of museums with complex shape (organic form), or the route is often labyrinthine or mixed type seems the most appropriate, it will however be necessary to find solutions for the winter and summer periods.

\subsection{The birth of the thermal topology:}

The segmentation method we have proposed in this paper has nothing to do with metric dimensions of space, it depends on changes in temperature in space. While looking for a meaning of this segmentation in the field of thermal, we found that this segmentation corresponds to what $O$. Gregory and $A$. Kumbaro (2013) had named the "thermal topology".

The thermal topology has not been evoked where to present in various works of urban planning or architecture, however it is related to the field of the physics of the buildings. The notion of topology designates the thermal balance, it is related to them different regimes of heat flow in the wall or within the space itself. Topology is used in Thermomotor simulations to qualify color (pixel) variations for each image rendering and each temperature. If we take the museum route in relation to the visitor's movement, we will notice that each segment corresponds to a specific temperature, or we pass from one temperature to another through a transition (a thermal event corresponding to the change in temperature) the segments in this case can be called "sequence", and we can thus define thermal topology as the transformations or 
discontinuities affecting the mean radiant temperature throughout route and we can then propose a new method of analysis based on temperature variation named sequential analysis. This new way of reading the space topologically will allow to qualify the architectural space from the thermal point of view "topologically", or within the route we can find several discontinuities based on the variations of temperatures.

This new methodological approach, linked to the thermal environment, can support simulation in order to improve the thermal performance of a design, or the study of a possible correction based on the micro (detail) and not the Marco (the whole project). The method of sequential analysis of ambient topologies (Saraoui.S, Belakehal, A, and al, 2018) had already been tested on the museum route for the sound and light ambiences.

\section{Conclusion:}

Museums are very important projects in our time, their importance emanates from the architectural aspect of the external form which plays a very important role in contemporary museums. If from a conceptual point of view the architect displays a particular intention for visual comfort and daylight in museum, the concept of thermal comfort remains ambiguous and often treated after the realization. However, it is essential to know how to choose the appropriate forms so that the piece of art do not deteriorate under the effect of variation of temperature and humidity.

The museum route is the link between the external architectural aspect and the interior of the museum space, whether it is an architect's choice, an imposed constraint or a result. It is the visitors' space on which the whole visit rests, the space in which visitors are invaded by sensations. This route can also be the place of variation of an essential element of comfort which is the mean radiant temperature influencing the visitors' feeling.

In this paper we have taken as elements to analyze the mean radiant temperature which gives an overall idea on the thermal comfort. We first analyzed the thermal comfort of the museums in question as a building, the results of this part seemed too general and without any particular relationship. The evaluation of the museum through its route, allowed us to detect the temperature differences that can characterize each type of museum, first for the periods of the most unfavorable days, then for each season. This allowed us to make recommendations for the choice of the form and the typology of route which goes with, this reflection related to the design of the museums makes it possible to reduce the consumption of energy.

Approaching the museum route by means of the segmentation method by mean radiant temperature interval, put the emphasis on a new methodological approach that can bring a new definition to the museum space based on the discontinuities or temperature differences that can characterize the route, This new way of reading space we have called "thermal topology" can define new spatiality of architectural space other than that based on dimension.

\section{Acknowledgement}

This research did not receive any specific grant from funding agencies in the public, commercial, or not-for-profit sectors.

\section{References}

Borie, A., \& Denieul, F. (1985). Méthode d'analyse morphologique des tissus urbains traditionnels I Morphological analysis method of traditional urban tissue]. Retrived from: http://unesdoc.unesco.org/images/0006/000 623/062310fb.pdf

Roger, C., \& D. Watson. (1979). L'habitat Bioclimatique : de la conception à la construction. [Bioclimatic habitat: from conception to construction.]. Montreal : l'Etincelle. Retrieved from: https://chocklamadefrea.firebaseapp.com/2 890191702.pdf

Cousin, J. (1980). L'Espace Vivant. Introduction à l'Espace Architectural Premier. [Living Space. Introduction to the Architectural Space Premier]. Paris: Le Moniteur. Retrieved from:

https://www.arc.ulaval.ca/files/arc/PIGEON JEAN-RAPHAEL-15.44.011.pdf

Hovig Ter Minassian. (2011) La réhabilitation thermique des bâtiments anciens à Paris. Comment concilier protection du patrimoine et performance énergétique? [ The thermal rehabilitation of old buildings in Paris: how to reconcile heritage protection and energy performance?]. Cybergeo: Revue européenne de géographie / European journal of geography, UMR 8504 Géographiecités, 2011, pp.1-19. <hal-01094810> https://journals.openedition.org/cybergeo/23 $\underline{737}$

Isaac, J. (2013). Museología y Museografía. Curso Universidad Nacional de Educación a 
Distancia. [Museology and museography. Course National University of Distance Education]. Montreal: (n.p). Retrieved from: http://portal.uned.es/portal/page?_pageid= 93,61703783\&_dad=portal\&_schema=PORTAL \&idAsignatura $=67024010$

Pigeon, J. (2013). Les transitions spatiales comme moteur de conception en habitation collective à Rimouski. [Spatial transitions as a collective housing design engine in Rimouski]. (Master dissertation, Laval University.) Retrieved from https://www.arc.ulaval.ca/files/arc/PIGEON JEAN-RAPHAEL-15.44.011.pdf

Corbusier, L. (1986). Towards a new Architecture. New York: Dover Publications. Retrieved from https://monoskop.org/images/b/bf/Corbusier _Le_Towards_a_New_Architecture_no_OCR.p $\underline{\mathrm{df}}$

Mariani-Roussset, S. (1996). la méthode des parcours dans les lieux d'exposition, l'espace urbain en méthode. [the method of the courses in the places of exhibition, the urban space in method]. Besancon: Research Center Human Space and Urban. Retrieved from

https://books.google.com.cy/books?id=0Wn ab5r9rVgC\&pg=PA44\&lpg=PA44\&dq=Mariani $=$

Rousset+1996\&source $=$ bl\&ots=wRVOF3bJvT\&si $\mathrm{g}=\mathrm{qgLdTd}$ Ln7ZfkWiBQcwdpWaCliRA\&hl=n|\&s

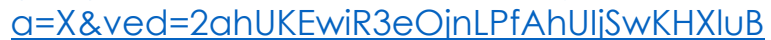
Y4Q6AEwCXoECAMQAQ\#v=onepage\& $\mathrm{q}=\mathrm{M}$ ariani-Rousset\%201996\&f=false

Michel Le Guay,(2009) fondation EFB, Le confort thermique. Les éditions parisiennes (EDIPA) http://docplayer.fr/10076900-Confortthermique-dans-les-lieux-de-vie-auteurmichel-le-guay.html

Panerai, P., Demorgon, M., \& Depaule, J. (1983), Analyse Urbaine. Marseille: Editions Parentheses.

Retrieved

from https://www.editionsparentheses.com/IMG/p $\mathrm{df} / \mathrm{p} 603$ analyse urbaine.pdf

Rahm, P. (2002). Decosterd \& Rahm. Bazel: Birkhauser Verlag Ag. Retrieved from https://www.bookdepository.com/Decosterd -Rahm-Physiological-Architecture-PhilippeRahm/9783764369446

Rahm, P. (2014). Constructed Atmoshpheres. Retrieved from http://www.postmediabooks.it/2014/124rahm Lphilipperahm.htm

Saraovi, S., Belakehal, A., Attar, A. \& Bennadji, A. (2018). Analysis and visualization of the new architectural spatiality: light and sound topologies in museums. In Chau, H.-W. and Hentschke, C. dos S. (eds.) Proceedings of the 7th international zero energy mass customer home conference 2018 (ZEMCH 2018), 29 January - 1 February 2018, Melbuourne, Australia. Melbourne: ZEMCH Network [online], pages 89-105. Retrieved from:

https://msd.unimelb.edu.au/ebooks/ZEMCH 2018 Conference Proceedings (20170123).pdf 